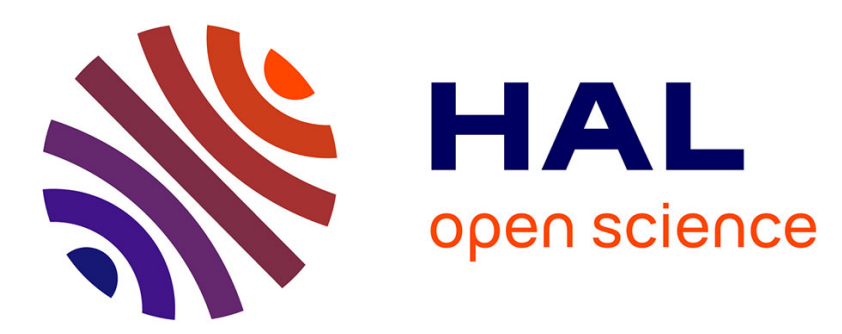

\title{
Effect of reinforcement shear and mesoscopic defects on the low velocity impact behavior of a GFRP
}

\author{
Bachir Kacimi, Arezki Djebbar, Samir Allaoui, Gilles Hivet, Fatiha Teklal
}

\section{To cite this version:}

Bachir Kacimi, Arezki Djebbar, Samir Allaoui, Gilles Hivet, Fatiha Teklal. Effect of reinforcement shear and mesoscopic defects on the low velocity impact behavior of a GFRP. International Journal of Material Forming, 2019, pp.3-17. 10.1007/s12289-019-01521-3 . hal-02563077

\section{HAL Id: hal-02563077 \\ https://hal.science/hal-02563077}

Submitted on 5 Sep 2021

HAL is a multi-disciplinary open access archive for the deposit and dissemination of scientific research documents, whether they are published or not. The documents may come from teaching and research institutions in France or abroad, or from public or private research centers.
L'archive ouverte pluridisciplinaire HAL, est destinée au dépôt et à la diffusion de documents scientifiques de niveau recherche, publiés ou non, émanant des établissements d'enseignement et de recherche français ou étrangers, des laboratoires publics ou privés. 


\title{
Effect of reinforcement shear and mesoscopic defects on the low velocity impact behavior of a GFRP.
}

\author{
Bachir KACIMI(a), Arezki DJEBBAR(a), Samir ALLAOUI(b)*, Gilles ${ }^{\left(a I^{(a)}\right.}{ }^{(\mathrm{C})}$, Fatiha TEKLAL(a) $^{(a)}$
}

(a) Laboratory of Mechanics, Structures and Energetics (L.M.S.E) University of Mouloud MAMMERI on Tizi Ouzou, BP 17 RP 15000, Tizi Ouzou, Algeria. bachir.kacimi@ummto.dz ; fatiha.teklal@ummto.dz ; arezki.djebbar@ummto.dz

(b) Institut de Thermique, Mécanique, Matériaux ; ITheMM - EA 7548, Université de Reims ChampagneArdenne, EiSINe, Campus Sud Ardenne, BP 50028, 08005 Charleville-Mézières Cedex, France. samir.allaoui@univ-reims.fr

(c) Laboratoire de mécanique Gabriel Lamé ; LaMé- EA 7494, Université d'Orléans, Polytech Orléans, 8 Rue Léonard de Vinci 45072 Orléans Cedex 2, France. gilles.hivet@univ-orleans.fr

*Corresponding author: samir.allaoui@univ-reims.fr

Keywords : A. Laminates; A. Fabric/textiles; B. Defects; B. Impact behavior; B. Mechanical properties.

\begin{abstract}
This paper presents an experimental study of the effect of mesoscopic buckles defect and shear deformation of the reinforcement, which result from forming, on the low velocity impact behavior of a composite laminate. The material studied is a glass/polyester composite with three layers of mat and one layer of taffeta fabric. To assess the properties induced on the final composite, plates with different amplitudes of calibrated defects and deformations were manufactured. First, the healthy material, which serves as a reference, was subjected to three levels of impact energy to observe the evolution of its behavior and damage mechanisms. Results of the impact tests and observations performed on the materials with calibrated defects identified a negative effect of buckling on elastic parameters and revealed greater damage relative to the healthy material. The reinforcement shear had a beneficial effect on the impact properties of the laminate, which was attributed to the increase in local fiber density.
\end{abstract}




\section{Introduction}

Composite materials with polyester matrix are increasingly used for structures in many industrial fields such as shipbuilding, aeronautics and the automotive sector due to their high specific performance/properties and their anisotropy, which can be adapted to the mechanical loadings undergone. In addition, the rapid growth in forming techniques for composite materials has contributed significantly to their widespread use. However, the characterization and mastery of the behaviors and damage processes of these materials, taking into account the effect of the manufacturing processes, remains a challenge when they are subjected to complex mechanical loadings.

The sensitivity of composite structures to low velocity impacts, which form part of these loadings, raises many concerns and restricts their scope of application. A structure can be exposed to shocks from various foreign bodies (of varying size, shape and rigidity) during the production, maintenance or service phases. These shocks generally cause internal damage that may be not visible on the surface of the structure, often with dramatic consequences on the mechanical performance of structures in service [1-5]. The three-dimensional nature of the effects of dynamic loading makes it sensitive to a large number of parameters, related to impact conditions or specific to the laminate, making it difficult to compare the various data published on the impact resistance of composite materials. Among the external parameters, the most important are the velocity [1, 6], the mass and the geometry of the impactor, linked by the incident kinetic energy of the impactor [7-9]. Depending on the combination of these parameters, the target response will be driven by different physical phenomena, which will cause different types of damage [7]. The main parameters intrinsic to the material are its geometry $[10,11]$, the type and content of the resin $[1,12]$, the nature of the fiber and interface $[1,12]$, the reinforcement architecture and the draping sequence [13-16].

However, to our knowledge, studies in this area do not take into account the effect of forming processes. In general, the composite materials tested are made under ideal conditions (stratification of undeformed fabrics and resin injection) without taking into account deformations and/or defects of the fibrous network. However, the fabric is mechanically loaded (tension, shear, bending, compaction, etc.) during forming, which can lead to residual deformations as well as the appearance of local defects on the reinforcement [17-21], especially when the geometry of the part is complex. 
forming defects can be divided in two types (Fig. 1): macroscopic defects (at the fabric scale) and mesoscopic defects (at the yarn scale). Macroscopic defects (wrinkles) have been widely studied in terms of phenomenology and their effect on the behavior of the final composite. Studies have shown that wrinkling, which is an out-of-plane phenomenon, is highly dependent on the coupling of shear/tension/bending/friction behaviors of the reinforcement [17, 22-29]. This defect, appearing at the reinforcement scale, generates a significant over-thickness that affects the geometrical tolerances and aesthetics of the final part. Furthermore, studies have shown that all mechanical properties induced on the final composite drops drastically, reaching up to $40 \%$ loss of maximum breaking stress [30-32]. The presence of wrinkles also leads to stress concentration phenomena that can cause premature damage [31, 33].

Mesoscopic defects appear locally at the yarn scale. Among these defects, we can distinguish yarn breakage, weave pattern heterogeneity, buckles, yarn waviness, etc. [18, 20, 30, 34, 35]. The behavior induced by these mesoscopic defects has a significant impact on the service life of the composite [36-41]. However, few studies deal with this aspect even though these mesoscopic defects are among the most recurrent when forming complex preforms [20, 21, 26, 28, 28, 29, 42]. In addition, when dealing with multilayer forming, inter-ply friction substantially increases their quantity and extent $[21,40]$, hence the importance of understanding the mechanisms involved and characterizing the criticality of these defects on the behavior of the final composite.

The present study addresses certain aspects of this problem by investigating the effect of buckling, a mesoscopic defect, and reinforcement shear on the composite impact behavior. Calibrated defects and shear were generated on glass fabric, taking care to reproduce the amplitudes observed during the forming of complex composite parts. Glass/polyester composite plates were manufactured by the contact molding process and then tested. The results and observations were analyzed and compared with those obtained on a healthy composite material in order to assess the effect of buckles defect and reinforcement shear on the behavior and damage generated. 


\section{Material and specimen preparation}

\subsection{Material}

The composite material used in this study is a GFRP from the company Iselman (Bejaïa, Algeria, www.iselman.com). It is mainly intended for the manufacture of marine navigation and fishing equipment. The same manufacturing process as that used by the company, namely contact molding, was used to produce composite plates with and without defects.

Three glass fabrics (two mat and one taffeta) manufactured by the Jushi group were used to manufacture the laminates. The two mats have a real weight of $300 \mathrm{~g} / \mathrm{m}^{2}$ and $450 \mathrm{~g} / \mathrm{m}^{2}$ with short fibers of 3 to $9 \mathrm{~cm}$. The taffeta has the following properties: a weight of $800 \mathrm{~g} / \mathrm{m}^{2}$, unbalanced fabric with 2.03 yarns/cm for warps and 1.62 yarns/cm for wefts, yarn width of $4.9 \mathrm{~mm}$ and $4.24 \mathrm{~mm}$ respectively for warp and weft. A thermosetting unsaturated polyester resin (Polylite ${ }^{\circledR} 440-800$ with a suitable Norpol Peroxide $\mathrm{N}^{\circ} 1$ hardener produced by Reichhold) was used to impregnate the various stacks.

To produce composite plates, a laminate of four layers, used to manufacture hulls and decks for $4.80 \mathrm{~m}$ fishing boats, was adopted. The order of the layers of this laminate is shown on Fig. 2. The impact tests were carried out on the outside face of the laminate (Fig. 2), which is subject to this type of loading during navigation.

\subsection{Specimen preparation}

Plates with calibrated defects were produced in accordance with the stacking arrangement of the reference laminate. Defects were generated only on the taffeta fabric. To reproduce the buckle defects, a machine developed in the LaMé laboratory was used. This machine consists of four automated axes that can be controlled, separately or simultaneously, in load or in displacement. After cutting a square reinforcement layer of $500 \times 500 \mathrm{~mm}^{2}$, the sample is clamped on the machine on both sides of the $\mathrm{x}$-axis (corresponding to the weft direction) by applying two identical and opposite loads, Fx and Fx'. On one side of the y-axis, a few warp yarns, in the central area of the sample, are clamped in a jaw (Fig. 3) and a Dy displacement, at a constant velocity, is applied (direction of the y-axis) while the opposite side remains free. The stretched warps pull the fibrous network thanks to the cohesion of the reinforcement. This results in negative displacements on the $\mathrm{x}$-axis $\left(\mathrm{Dx}\right.$ and $\left.\mathrm{Dx}^{\prime}\right)$ which induce opposite shearing of the reinforcement on either side of the central axis of the sample, but with equal absolute values. 
Consequently, the weft yarns are subjected to bending, which generates their out-of-plane buckling in the central area, thus creating the buckle defect (Fig. 3). After reaching the required amplitude of defects, the test is stopped and a fixing agent is sprayed on the surface of the sample. The sample with calibrated defects can then be removed and cut to $350 \times 350 \mathrm{~mm}^{2}$ for use as a ply in the final composite.

The defects were generated in such a way as to reproduce the amplitudes observed in a feasibility study of a complex part for nautical applications. Plies were made with shear angles of $10^{ \pm 1^{\circ}}, 20^{ \pm 1^{\circ}}$ and $30^{ \pm 1{ }^{\circ}}$ on each of the zones delimiting the buckle band as the amplitude of the defect is proportional to this shear (Fig. 3).

To produce the specimens, healthy and calibrated laminates with defects and deformation were produced using the contact molding process and respecting the same order of plies as the reference material (Fig. 2). The final average thickness of the composite plates obtained was about $3.7 \pm 0,15 \mathrm{~mm}$. Rectangular specimens for impact tests, measuring $150 \mathrm{~mm}$ x $100 \mathrm{~mm}$ according to ASTM D 7136 / ASTM D 7136M-12 [43], were then cut out with a water jet on the plates. The longitudinal direction of these specimens corresponds to the direction of the warps. Three batches, labelled according to their area of provenance, were cut out (Fig. 4):

- Batch A: healthy specimens cut on the reference plates without defects.

- Batch AB: specimens cut from the band with the buckle defect.

- Batch AS: specimens cut on the sheared areas of the plates with calibrated defects.

The fiber content of the reference laminate is $40 \pm 2 \%$. For batch AS, an increase in fiber rate, due to the shear of these areas compared to the reference material is estimated at $6.68 \%, 2.77 \%$ and $0.66 \%$ respectively for the shear angles of $30^{\circ}, 20^{\circ}$ and $10^{\circ}$. Concerning batch $\mathrm{AB}$, the rate remains practically unchanged due to the low shear rates in this area.

\section{Impact tests}

The mechanical impact tests were performed using an instrumented drop tower machine, model Instron Dynatup 9250 HV (Fig. 5). The specimens were centered on a frame and blocked by a plate, with a clamping system, with a rectangular window of $125 \mathrm{~mm}$ x $75 \mathrm{~mm}$. The center of the specimens was 
impacted with a hemispherical impactor with a mass of $14 \mathrm{~kg}$ and a diameter of $50.8 \mathrm{~mm}$. The tests were performed with three impact energy levels (10J, 20J and 30J), while maintaining the mass of the impactor constant. Five samples were impacted for each test configuration.

The samples subjected to the impact were visually analyzed and then the height of the profiles of the damaged areas after impact was measured with an interferometer. This height is the difference between the maximum height of the profile of the damaged area and the surface of the plate (Fig. 6). It was measured on the side opposite the impacted surface.

Internal damage was observed under a scanning electron microscope operating in environmental mode. The device used was a Philips ESEM XL 30. The acceleration voltage of the electrons was 10 to 20 $\mathrm{kV}$.

\section{Results and discussion}

\subsection{Reference material}

The reference laminate was tested for low impact energies (low impact velocity) to observe the evolution of its response as a function of the incident energy. Fig. 7 highlights the variation in the impact properties according to the three energies used 10J, 20J and 30J. Good reproducibility of the results for the drop weight impact test was observed for the same material.

It was found that the evolution of impact characteristics increased with the impact energy (Fig. 7). The loading and unloading regions were almost symmetrical (Fig. 7a), suggesting that the contact duration is almost unchanged. Higher impact velocities induced a larger impact force and therefore a larger deformation. This indicates that the impact velocity dominates the impact energy but has little effect on the contact duration, which is governed by the material properties $[44,45]$.

The rising part of the curves (Fig. 7b) corresponds to the loading phase of the material up to a maximum value equivalent to the impact energy. The impactor meets the sample and its velocity decreases until it reaches $0 \mathrm{~m} / \mathrm{s}$ (Fig. 7d). At that time, the impactor has reached its maximum displacement. Following this, the impactor bounces back and its velocity becomes negative (Fig. 7d), which generates a decrease in energy corresponding to the unloading phase initiated by the bouncing (Fig. 7b). It can also be seen that after about $14 \mathrm{~ms}$ the energy stabilizes, indicating that the impactor has lost contact with the sample. Some of the energy has been restored in an elastic way. The residual energy then 
corresponds to the energy dissipated by the damage of the laminate, represented by the area under the curves in Fig. 7e which increases proportionally with the impact energy.

The slope of the ascending section of each force-deflection curve (Fig. 7e) represents the impact bending stiffness of the laminated composites $[46,47]$. These curves also show the response of the material subjected to an impact load, indicating the bouncing of the impactor off the sample surface, which results in closed curves [48]. Curves of this type return to the origin of the diagram after the descending section of the maximum load (Fig. 7e). In addition, all the samples have a very similar initial response before the maximum load is reached.

The beginning of damage in the material is associated with a change in the initial slope and the presence of an incipient break point on the force-deflection curves [49]. This damage is shown in the curves of the specimens subjected to 20J and 30J where a load drop occurs followed by an increase (Fig. 7e). The non-linearity in these curves at energies of $20 \mathrm{~J}$ and $30 \mathrm{~J}$ clearly indicates an increase in stiffness that may be associated with strain-rate and laminate thickness effects on impact $[44,50]$. Chen et al. showed that the contact stiffness for relatively thin laminates does not remain constant but increases as the impact force increases and the amplitude of the variation is dominated by the difference in deflection between the contact center and the support boundary [50].

Table 1 provides a summary of the average measurements (load, energy absorbed, displacement, area damaged...) during impact tests for the three energy levels of the reference material. The percentage given in brackets after the heights of the damaged profile (Table 1) represents the size of each height in relation to the initial thickness of the specimen. We note that the maximum load, maximum deflection, absorbed energy and damaged areas generated after impact evolve linearly with the impact energy for this type of material (Fig. 8).

Visual analysis of the impacted areas highlights damage of the matrix and delamination areas. In addition, several fiber breakages appear from the impact energy of 20J (Fig. 9). Damaged areas increase linearly with impact energy (Fig. 8); their extent is greater in the weft direction. This is due to the presence of gaps between the wefts (and thus resin-rich regions) and the boundary conditions applied in their direction (clamping system with a rectangular window) which promotes the propagation of delamination. In contrast, the impacted face has no visible macro-cracks on the surface. 
The results of the visual analysis were confirmed by the SEM observations, showing that the size of the damaged areas increases proportionally to the impact energy (Fig.10). This damage is present on the faces opposite to the impact. The faces show fiber breakage and multiple cracks and fragmentation of the matrix combined with fiber/matrix debonding. These damage mechanisms are those classically found during an impact on composites.

\subsection{Comparison between healthy materials and materials with calibrated defects and shear}

After characterizing the behavior of the healthy composite, impact tests were conducted to characterize the properties induced by the calibrated buckling ( $\mathrm{AB}$ samples) as well as the shear deformation (AS samples) of the reinforcement. This effect was characterized at 3 amplitude levels corresponding to shears of $10^{\circ}, 20^{\circ}$ and $30^{\circ}$. The comparison was done at impact conditions of $20 \mathrm{~J}$, as this generates different damage, as was seen previously.

Fig. 11 presents the impact behavior of samples with calibrated defects and shear obtained for the $30^{\circ}$ configuration $\left(\mathrm{AB} 30^{\circ}\right.$ and $\left.\mathrm{AS} 30^{\circ}\right)$ compared to those of the healthy material (A). Despite almost symmetrical behavior, there is a variation in the maximum load (Fig. 11a): the maximum load of the specimens with shear reinforcement (AS) is slightly higher than that measured for the reference laminate (A), which is attributed to the increase in the stiffness of the laminate. This is confirmed by the increase in the upward slope of the load-deflection curves, representing the impact bending stiffness of the laminated composites (Fig. 11e).

This increase in stiffness is attributed to the effect of reinforcement shear which induces an increase in fiber content (by $6.68 \%$ in this case) associated with the contribution of transverse yarns to mechanical behavior in the longitudinal direction of the material. For healthy specimens (batch A), only the yarns in the longitudinal direction contribute to the stiffness of the material in this direction, while for specimens in batch AS, the transverse yarns, being reoriented, provide additional stiffness $[39,40]$. This increase in stiffness also results in a decrease in the maximum deflection undergone by the material (Fig. 11c and 11e). This is the case even if the evolution of the incidence velocity remains substantially unchanged (Fig. 11d).

The trend is reversed for specimens with buckling defects $(\mathrm{AB})$ where a maximum load reduction of about 5\% was measured (Fig. 11a) as well as a decrease in stiffness (Fig. 11e). This indicates that the 
effect of buckling is not negligible on the mechanical impact behavior of the composite as is also the case for fatigue behavior $[39,40]$. This decrease in stiffness results in a more pronounced deflection for laminates with buckles (Fig. 11c).

This effect is attributed to the nature of the defect, which consists of a local disorganization of the fibrous network, with a reorientation of the fibers following the out-of-plane buckling of the yarns. In addition, this reorganization creates a local fiber impoverishment that favors resin-rich areas (Fig. 3) at the point of impact and along the centerline of the sample. All these phenomena lead to a decrease in the material's mechanical performance because the taffeta, with defects, is subjected to a tensile load as it is located on the lower part opposite the impacted side (Fig. 2).

In addition, this drop in performance is associated, by the nature of the defect, with a greater predisposition to damage leading to higher absorbed energy for the laminate with defects than for the healthy material (Fig. 11b).

Table 2 presents a summary of the average measurements (load, absorbed energy, displacement, damaged area) during the impact tests performed on the AS and AB material batches, with different defect and shear amplitudes. As a reminder, the amplitude of the buckling was controlled by shearing the reinforcement.

These results illustrate an evolution of all the mechanical parameters as a function of the amplitude of the buckling for $\mathrm{AB}$ specimens and of the shear rate for the AS batch (Table 1), in relation to the healthy material.

Thus, the maximum impact load of the $\mathrm{AB}$ specimens decreases proportionally to the amplitude of the defect due to the loss of bending stiffness generated by buckling (Fig. 12). This decrease is quasi-linear up to a defect amplitude corresponding to a shear angle of $20^{\circ}$ where a change in the slope of the load evolution is observed (Fig. 12). This buckling amplitude (at $20^{\circ}$ ) can therefore be considered as a threshold for the sizing of composite parts.

The reduction in the maximum load caused by a disorientation of the fibrous network associated with the presence of resin-rich areas causes an increase in the absorbed energy following the damage of the 
composite (Fig. 13). An over-thickness of the specimen (an excess of resin during molding) can also affect the amount of energy absorbed.

For specimens with calibrated shear (AS batch), the trend is inverted. The maximum load increases while the dissipated energy decreases as a function of the reinforcement shear, compared to the healthy material. As explained above, this is due to the increase in the local fiber content of the material as well as the stiffness contribution of the transverse yarns in the longitudinal direction.

During the impact tests, the energy is dissipated in the form of damage that manifests itself in all three material directions $[51,52]$. The damage is therefore proportional to the rates of dissipated energy. Visual analysis of the impacted areas of the specimens highlights matrix breakage and delamination areas, as well as fiber breakage (Fig. 14). The shapes of the damaged areas of batches AB and AS are different from those of healthy specimens. Delamination follows the direction of the yarns and leads to less circular shapes. The extent of the damaged area is greater along the loop band for samples with defects (AB), and along the weft yarns for sheared samples (AS batch). The impacted face has no visible macro-cracks on the surface except a circular indentation caused by the hemispherical head of the impactor.

The extent of these damaged areas for batches $\mathrm{AB}$ and $\mathrm{AS}$ is smaller than that of the healthy material. In the $10^{\circ}$ configuration of batch $\mathrm{AB}$, there is a $27 \%$ decrease in the damaged area compared to the healthy material, while the dissipated energy has increased (Table 2 and Fig. 15). This is because buckling predisposes the material to damage in the thickness.

This is evidenced by the fact that the height of the damaged profile, on the side opposite to the impact, for batch $\mathrm{AB}$ at $10^{\circ}$ represents $51 \%$ of the total thickness of the sample against only $35 \%$ for the healthy material impacted at 20J (Table 1). We attribute this to the presence of resin-rich areas, which are easily damaged, combined with the out-of-plane buckling of the yarns, which favors the propagation of an outof-plane damage mode to the detriment of in-plane damage of the material.

This fact was verified with the help of the SEM observations, which were made in the thickness of the samples along two cutting planes (longitudinal and transverse) passing through the center of the buckled regions. These observations showed the presence of significant damage, located on the opposite side, with numerous fiber breakages, multiple cracks and fragmentation of the matrix, combined with a fiber/matrix debonding (Fig. 16). These fractographies also highlighted the presence of resin-rich areas whose extent 
increases with the amplitude of the buckling. Note that the damage increased proportionally with the defect amplitude (Fig. 16) until the height of the damaged profile reached up to $88 \%$ of the material thickness for the $30^{\circ}$ configuration (Table 2).

In the case of samples with sheared reinforcement, there is also a decrease in the damaged area $(29 \%$ reduction compared to healthy material) and a slight increase in the height of the damaged profile ( $40 \%$ against 35\% for healthy material) (Table 1 and Table 2). The deformation of the reinforcement was beneficial to the strength of the material by reducing damage in the plane of the material, which led to a slight increase in out-of-plane damage.

This can be explained by the increase in the local fiber rate due to shear deformations. The shear of interlaced yarns generates several lateral fiber contacts, resulting in nodes at crossover points that induce stress concentrations, which limits the growth of delamination. Therefore, the shear deformations contribute to slowing down the damage propagation in the transverse direction. This phenomenon is confirmed by the relative position of the taffeta reinforcement compared to the laminate. It can be seen on the fractographies that the taffeta has practically not been deformed in the out of plane dimension (Fig. 17) unlike the $A B$ specimens where a disorganization of the meso-architecture is observed (Fig. 16). The same damage mechanisms as before were observed for the sheared specimens (AS) but with a higher fiber/matrix debonding compared to materials A and AB (Fig. 17). The damage increases proportionally with the amplitude of the shear angle.

\section{Conclusions}

Forming processes induce residual deformations on the reinforcement and sometimes lead to mesoscopic defects, which are more recurrent than macroscopic defects during the manufacture of complex structural parts. This work contributes to the study of the effect of these defects and deformations, through the example of buckling, as well as shear deformations on the low velocity impacts.

The results of the impact tests showed that buckling has a negative effect on the elastic parameters of the material. This effect is the consequence of a local fiber impoverishment and a disorganization of the fibrous network, with a reorientation of the fibers following the out-of-plane buckling of the yarns, in the area where the defects are located. The loss of mechanical performance increases with the amplitude of 
the defect. It was noted that the amplitude of the defect proportional to a $20^{\circ}$ shear of the lateral zones could be considered as a critical point beyond which the loss of stiffness follows a more pronounced trend.

For the material with calibrated shear of the reinforcement, the significant contribution to stiffness of the transverse yarns and the increased local fiber rate due to the shear deformations led to an increase in mechanical properties.

The SEM observations made on the impacted specimens highlighted significant damage in the out-ofplane mode, both in the case of specimens with buckles and those with shear, relative to the healthy material where in-plane damage predominates. The damage is proportional to the amplitude of the defects and the shear, and leads to less circular damaged areas because of their propagation along the fibrous network that has been disorganized.

\section{Conflict of Interest}

The authors declare that they have no conflict of interest.

\section{References}

[1] Cantwell WJ, Morton J. (1991) The impact resistance of composite materials - A review. Composites; 22:347-362.

[2] Kaczmarek H, Maison S. (1994) Comparative ultrasonic analysis of damage in CFRP under static indentation and low velocity impact. Compos Sci Technol; 51:11-26.

[3] Tai NH, Yip MC, Lin JL (1998) Effects of low-energy impact on the fatigue behaviour of carbon/epoxy composites, Compos Sci Tech; 58:1-8.

[4] Abrate S. (2005) Impact on Composite Structures. Cambridge university press.

[5] Zhang ZY, Richardson MOW. (2007) Low velocity impact induced damage evaluation and its effect on the residual flexural properties of pultruded GRP composite. Compos struct; 81:195-201.

[6] Cantwell WJ, Morton J. (1989) Comparison of the low and high velocity impact response of CFRP. Composites; 20(6):545-551. 
[7] Olsson R. (2000) Mass criterion for wave control impact response of composite plates. Compos Part AAppl Sci Manuf; 31:879-887.

[8] Mitrevski T, Marshall IH, Thomson R, Jones R, Whittingham B. (2005) The effect of impactor shape on the impact response of composite laminates. Compos Struct; 67:139-148.

[9] Mitrevski T, Marshall IH, Thomson R, Jones R. (2006) Low-velocity impacts on preloaded GFRP specimens with various impactor shapes. Compos Struct; 76:209-217.

[10] Guillaumat L. (2000) Reliability of composite structures-Impact loading. Comput Struct; 76:163-172. [11] Liu KS, Tsai SW. (1998) A progressive quadratic failure criterion for a laminate. Compos Sci Technol; 58:1023-1032.

[12] Richardson MOW, Wisheart MJ. (1996) Review of low-velocity impact properties of composite materials. Compos Part A; 27:1123-1131.

[13] González EV, Maimí P, Camanho PP, Lopes CS, Blanco N. (2011) Effects of ply clustering in laminated composite plates under low velocity impact loading. Compos Sci Technol; 71:805-817.

[14] Tan KT, Watanabe N, Iwahori Y, Ishikawa T. (2012) Effect of stitch density and stitch thread thickness on compression after impact strength and response of stitched composites. Compos Sci Technol; 72:587-598.

[15] Sanchez-Saez S, Barbero E, Zaera R, Navarro C. (2005) Compression after impact of thin composite laminates. Compos Sci Technol; 65:1911-1919.

[16] Aktas M, Karakuzu R, Arman Y. (2009) Compression-after impact behavior of laminated composite plates subjected to low velocity impact in high temperatures . Compos Struct; 89:77-82.

[17] Allaoui S, Boisse P, Chatel S, Hamila S, Hivet G, Soulat D, Vidal-Salle E. (2011) Experimental and numerical analyses of textile reinforcement forming of a tetrahedral shape. Compos Part A- Appl Sci Manuf; 42:612-622.

[18] Lightfoot JS, Wisnom MR, Potter K. (2013) Defects in woven preforms: Formation mechanisms and the effects of laminate design and layup protocol. Compos Part A- Appl Sci Manuf; 51:99-107.

[19] Ouagne P, Soulat D, Moothoo J, Capelle E, Gueret S. (2013) Complex shape forming of a flax woven fabric; analysis of the tow buckling and misalignment defect. Compos Part A- Appl Sci Manuf; 51:1-10. 
[20] Allaoui S, Hivet G, Soulat D, Wendling A, Ouagne P, Chatel S. (2014) Experimental performing of highly double curved shapes with a case corner using an interlock reinforcement. Int J Mater Form; 7:155165.

[21] Allaoui S, Cellard C, Hivet G. (2015) Effect of inter-ply sliding on the quality of multilayer interlock dry fabric. Compos Part A- Appl Sci Manuf;68:336-345.

[22] Prodromou AG, Chen K. (1997) On the relationship between shear angle and wrinkling of textile composite preforms. Compos Part A; 28:491-503.

[23] Wang J, Paton R, Page J.R. (1999) The draping of woven fabric preforms and prepregs for production of polymer composite components. Compos Part A- Appl Sci Manuf;30:757-765.

[24] Potluri P, Sharma S, Ramgulam R. (2001) Comprehensive drape modeling for molding 3D textile preforms. Compos Part A- Appl Sci Manuf; 32:1415-1424.

[25] Sharma SB, Sutcliffe MPF, Chang SH. (2003) Characterization of material properties for draping of dry woven composite material. Compos Part A- Appl Sci Manuf; 34:1167-1175.

[26] Ten Thije RHW, Akkerman R, Huétink J. (2007) Large deformation simulation of anisotropic material using an updated lagrangian finite element method. Compos Methods Appl Mech Eng; 196:3141-3150.

[27] Hamila N, Boisse P. (2008) Simulations of textile composite reinforcement draping using a new semi discrete three node finite element. Compos Part B - Eng ; 39:999-1010.

[28] Wilems A, Lomov S, Verpoest I, Vandepitte D, Harrison P, Yu WR. (2008) Forming Simulation of a thermoplastic commingled woven textile on a double dome. Int J Mater Form; 1:965-968.

[29] Boisse P, Hamila N, Vidal-Sallé E, Dumont F. (2011) Simulation of wrinkling during textile composite reinforcement forming. Influence of tensile, in-plane shear and bending stiffness. Compos Sci Tech; 71:683-692.

[30] Potter K, Khan B, Wisnom M, Bell T, Stevens J. (2008) Variability fibre waviness and misalignment in the determination of the properties of composite materials and structures. Compos Part A- Appl Sci Manuf; 39:1343-1354. 
[31] Bloom LD, Wang J, Potter KD. (2013) Damage progression and defect sensitivity: an experimental study of representative wrinkles in tension. Compos Part -B Eng; 45:449-458.

[32] Hallander P, Akermo M, Mattei C, Petersson M, Nyman T. (2013) An experimental study of mechanisms behind wrinkle development during forming of composite laminates. Compos Part A- Appl Sci Manuf; 50:54-64.

[33] Mukhopadhyay S, Jones M.I, Hallett S.R. (2015) Tensile failure of laminates containing an embedded wrinkle; numerical and experimental study. Compos Part A- Appl Sci Manuf; 77:219-228.

[34] Gatouillat S, Bareggi A, Vidal-Sallé E, Boisse P. (2013) Meso modelling for composite preform shaping-simulation of the loss of cohesion of the woven fiber network. Compos Part A-Appl Sci Manuf; 54:135-144.

[35] Tephany C, Gillibert J, Ouagne P, Hivet G, Allaoui S, Soulat D. (2016) Development of an experimental bench to reproduce the tow buckling defect appearing during the complex shape forming of structural flax based woven composite reinforcements. Compos Part A- Appl Sci Manuf; 81:22-33.

[36] Piggott MR. (1995) The effect of fiber waviness on the mechanical properties of unidirectional fiber composite: a review. Compos Sci Tech; 53:201-205.

[37] Hsiao HM, Daniel IM. (1996) Elastic properties of composites with fibre waviness. Compos Part A; 27:931-941.

[38] Wang J, Potter K, Hazra K, Wisnom W. (2012) Experimental fabrication and characterization of outof-plane fiber waviness in continuous fiber-reinforced composites. J Compos Mater; 46:2041-2053.

[39] Allaoui S, Hivet G, Haddad M, Agogué R, Khellil K, Beauchene P, Aboura Z. (2015) Effect of the buckles mesoscopic defects on the composite properties. In ICCM-20. Copenhagen, July, 2015.

[40] Cruanes C, Shanwan A, Méo S, Allaoui S, Deffarges MP, Lacroix F, Hivet G. (2018) Effect of mesoscopic out-of-plane defect on the fatigue behavior of a GFRP. Mech Mater; 117:214-224.

[41] Wisnom MR, Atkinson JW. (2000) Fibre Waviness Generation and Measurement and Its Effect on Compressive Strength. J Reinf Plast Compos;19(2):96-110. 
[42] Capelle E., Ouagne P., Soulat D., Duriattic D. (2014) Complex shape forming of flax woven fabrics:

Design of specific blank-holder shapes to prevent defects. Compos Part - B Eng; 62:29-36.

[43] ASTM standard D7136/D7136M-12. Standard test method for measuring the damage resistance of fiber-reinforced polymer matrix composite to a drop-weight impact event. American Society for Testing and Materials 2012.

[44] Gong SW, Shim VPW, Toh SL. (1998) Determining effective contact stiffness between striker and composite shell. Compos Struct; 43:137-145.

[45] Reyes G, Sharma U. (2010) Modeling and damage repair of woven thermoplastic composites subjected to low velocity impact. Compos Struct; 92:523-531.

[46] Liu D, Raju BB, Dang X. (2000) Impact perforation resistance of laminated and assembled composite plates. Int J Impact Eng; 24:733-746.

[47] Taraghi I, Fereidoon A, Taheri-Behrooz F. (2014) Low-velocity impact response of woven Kevlar/epoxy laminated composites reinforced with multi-walled carbon nanotubes at ambient and low temperatures. Mater Des; 53:152-158.

[48] Sayer M, Bektas NB, Demir E, Çallioğlu H. (2012) The effect of temperatures on hybrid composite laminates under impact loading. Compos Part B - Eng; 43:2152-2160.

[49] Chou S, Chen HC, Chen HE. (1992) Effect of weave structure on mechanical fracture behavior of threedimensional carbon fiber fabric reinforced epoxy resin composites. Compos Sci Technol; 45(1):23-35.

[50] Chen P, Xiong J, Shen Z. (2008) Thickness effect on the contact behavior of a composite laminate indented by a rigid sphere. Mech Mater; 40:183-194.

[51] Garcea S.C, Mavrogordato M.N, Scott A.E, Sinclair I, Spearing S.M. (2014) Fatigue micromechanism characterisation in carbon fiber reinforced polymers using synchrotron radiation computed tomography. Composi Sci Technol; 99:23-30.

[52] Garcea S.C, Sinclair I, Spearing S.M. (2015) In situ synchrotron tomographic evaluation of the effect of toughening strategies on fatigue micromechanisms in carbon fiber reinforced polymers. Compos Sci Technol; 109:32-39. 


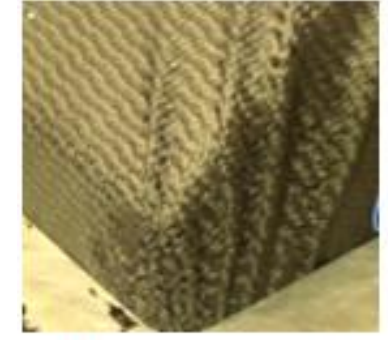

Wrinkles [21]

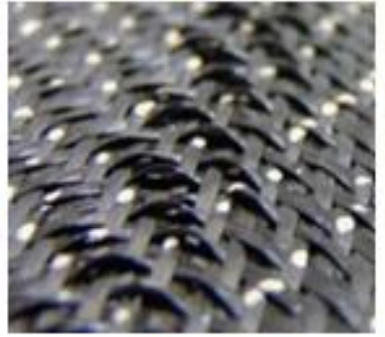

Buckles [20]

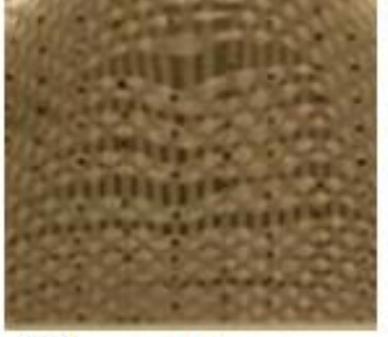

Weave pattern heterogeneity [20]

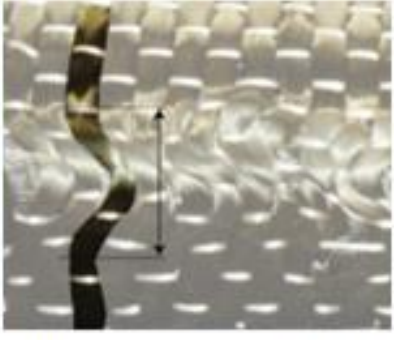

Yarn waviness [18]

Fig. 1. Shaping defects: Macroscopic (wrinkles) and Mesoscopic

Inside face

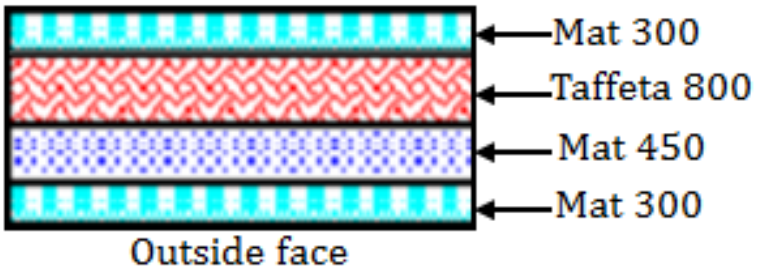

Fig. 2. Order of the reference laminate layers. 


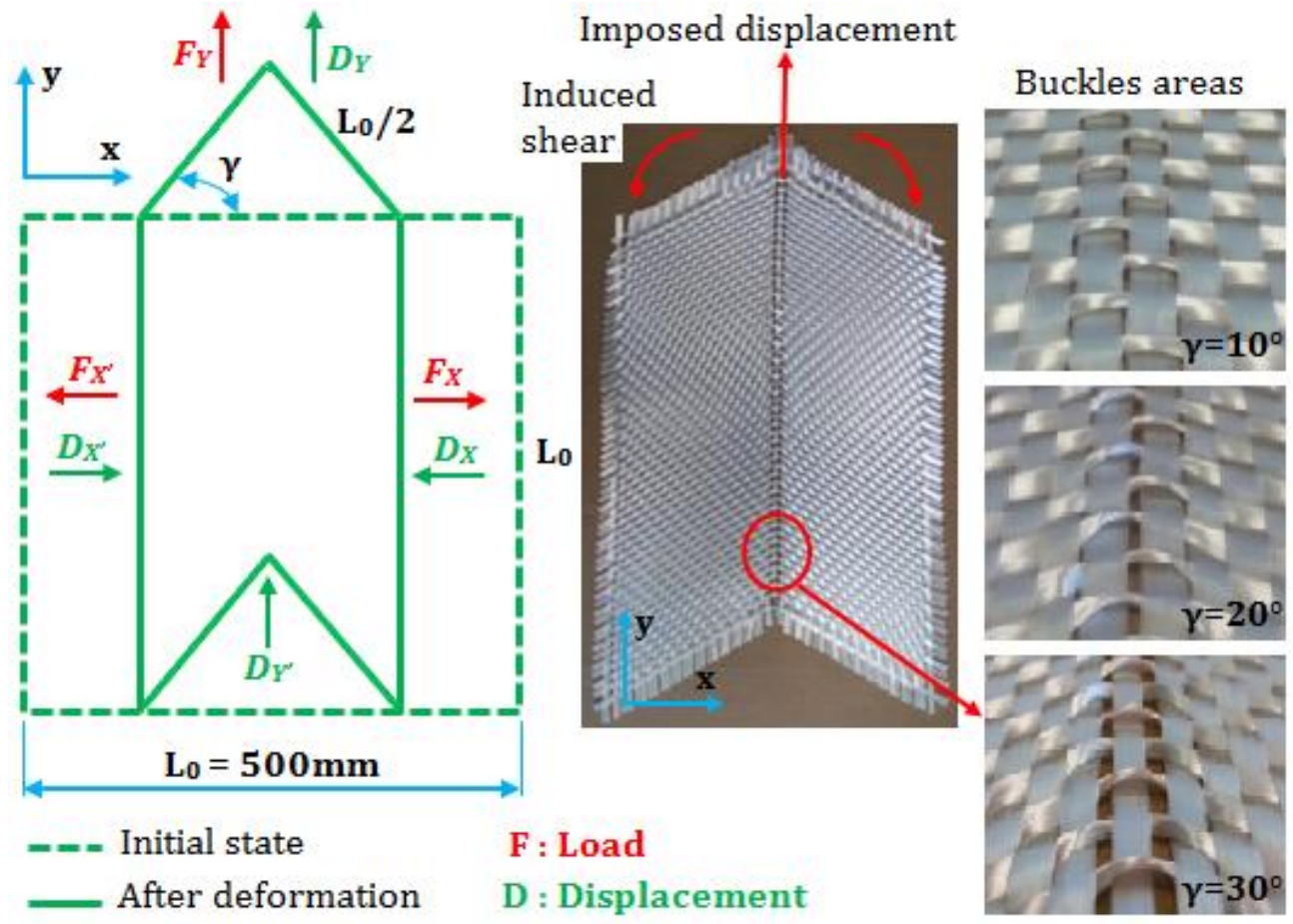

Fig. 3. Protocol for making calibrated specimens.
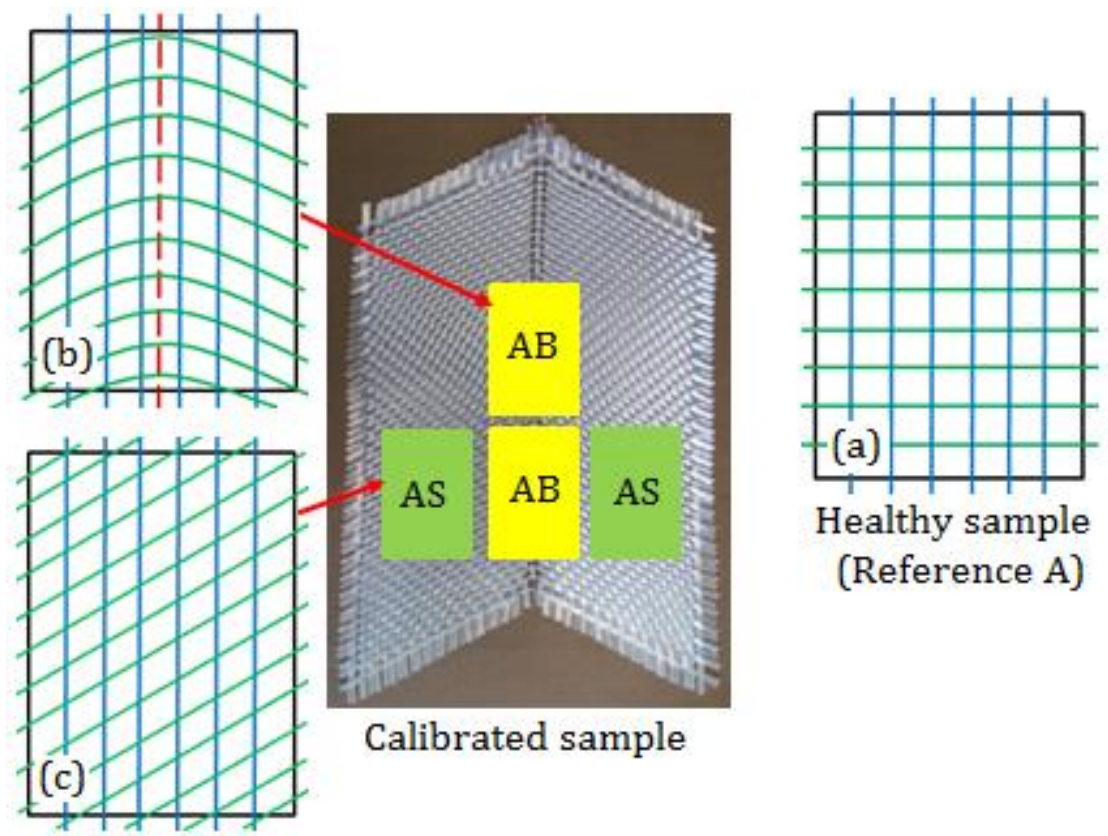

Fig. 4. Cutting area and schematization of specimens: a) healthy, b) with buckles defect and c) sheared. 


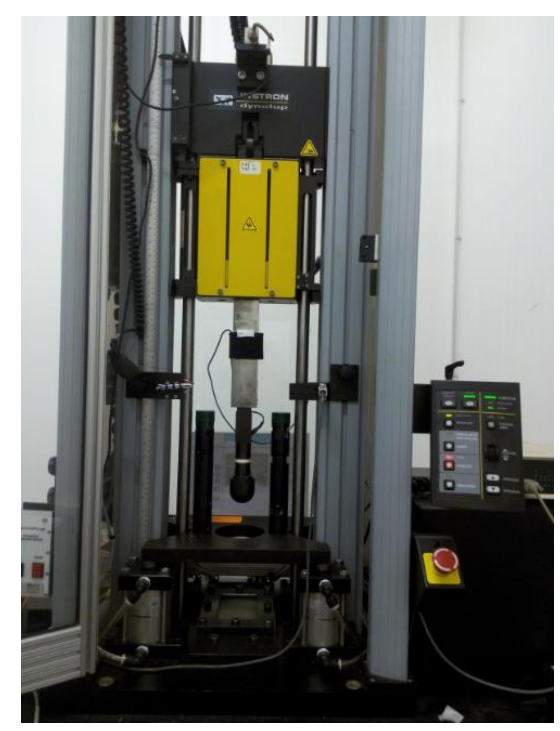

Fig. 5. Instrumented dropping weight impact tower.

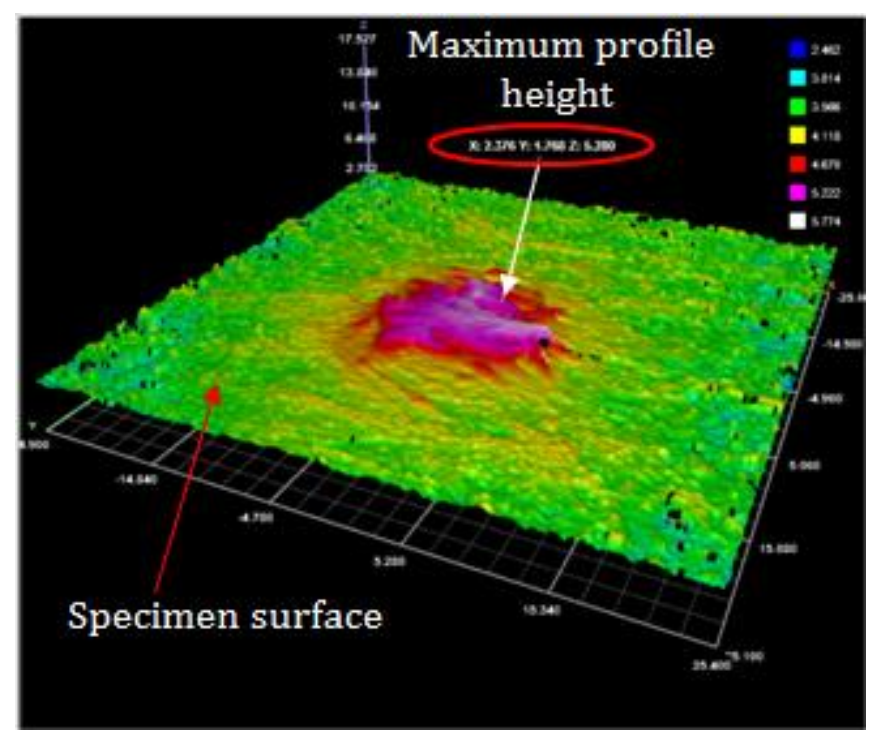

Fig. 6. Image of a damaged profile obtained with the interferometer. 

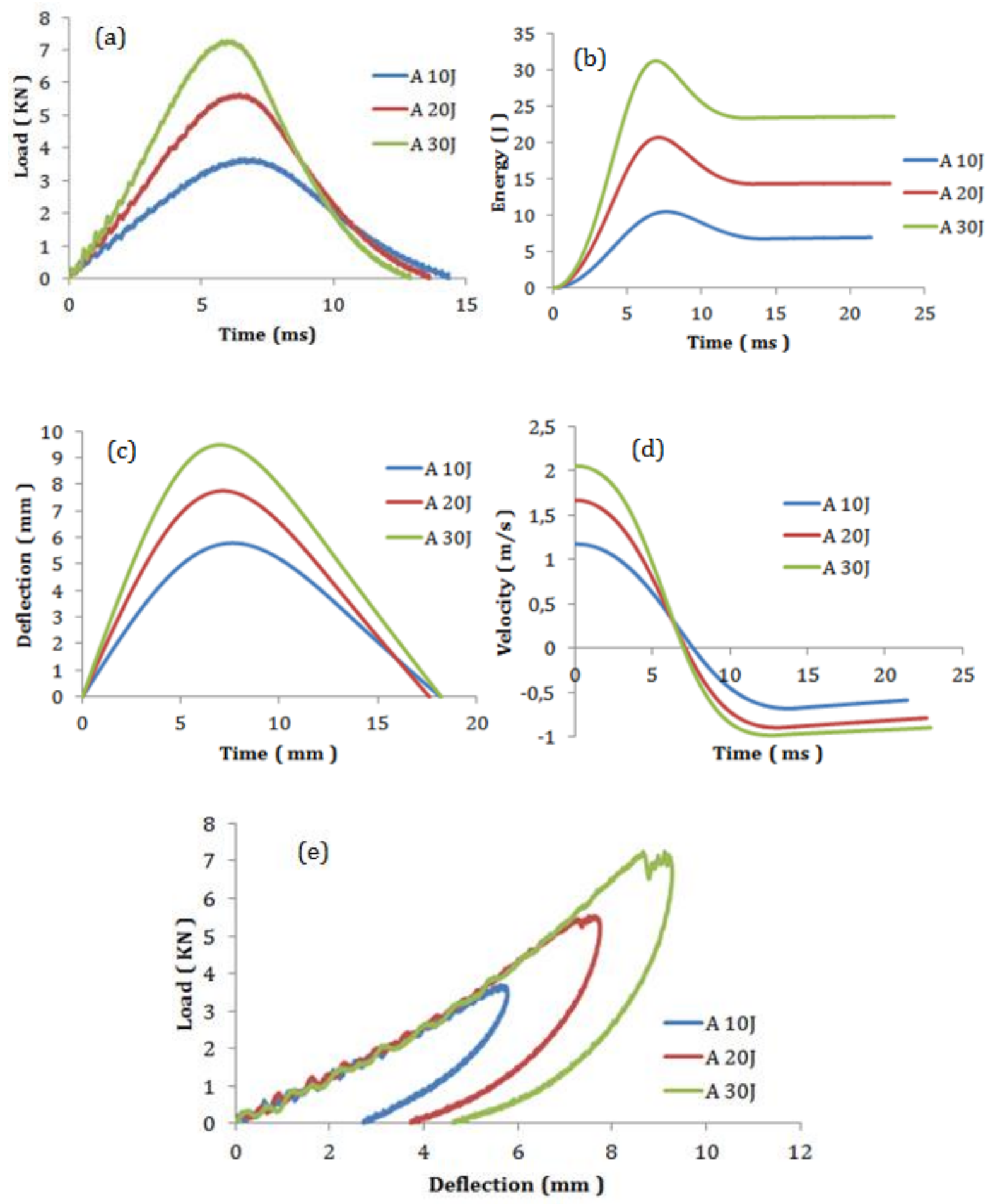

Fig. 7. Evolution of load vs. time (a), energy vs. time (b), deflection vs. time (c), velocity vs. Time (d), load vs. deflection (e) for the three levels of impact energy. 


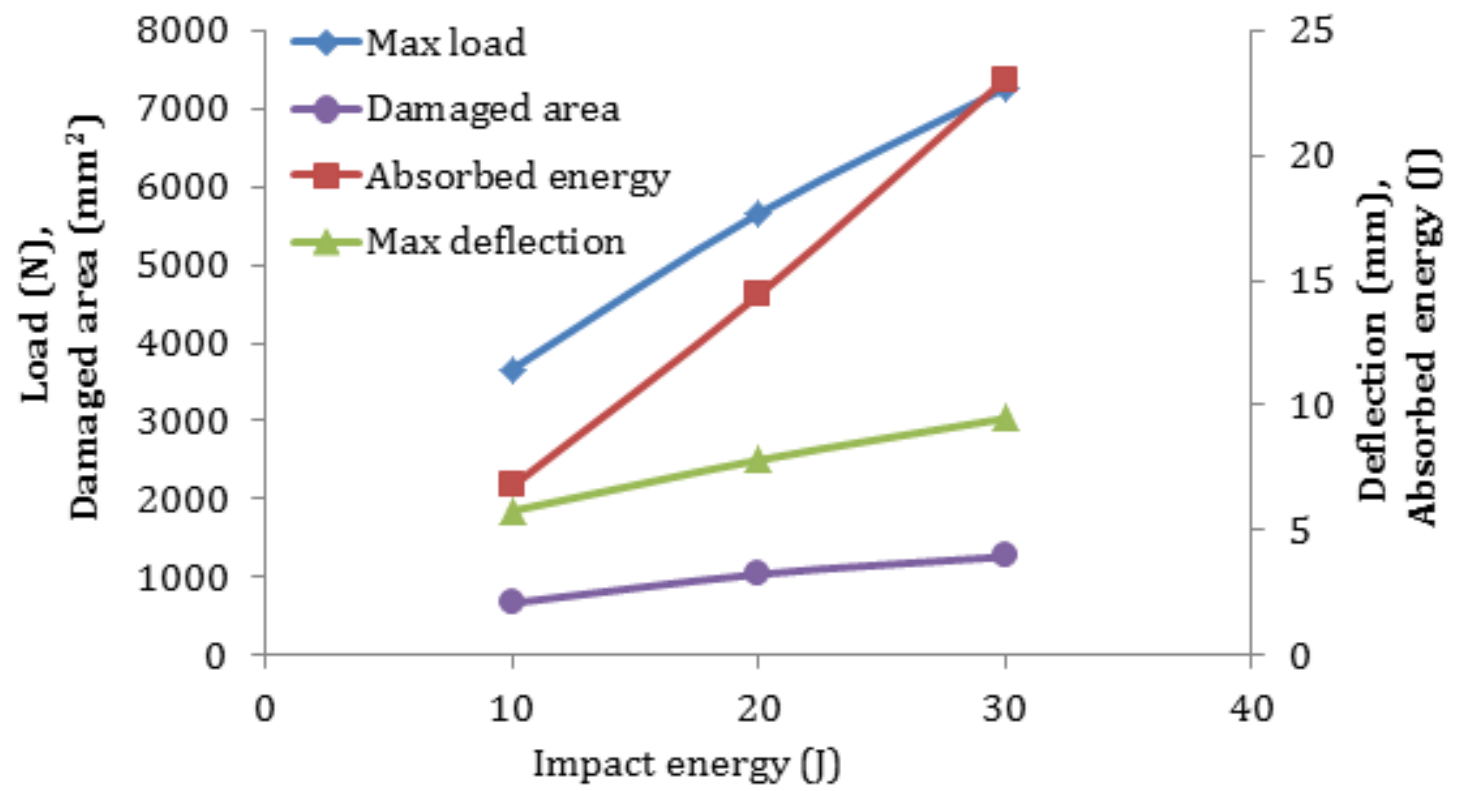

Fig. 8. Evolution of impact characteristics as a function of the impact energy of batch A
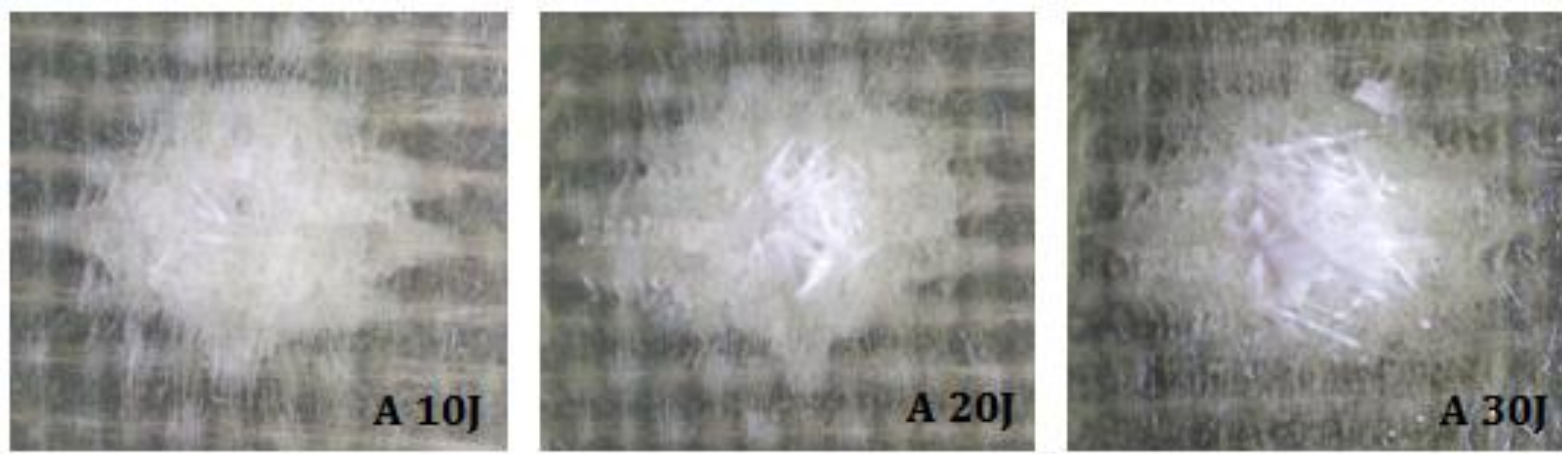

Fig. 9. Evolution of impact damages as a function of the impact energy for batch A. 

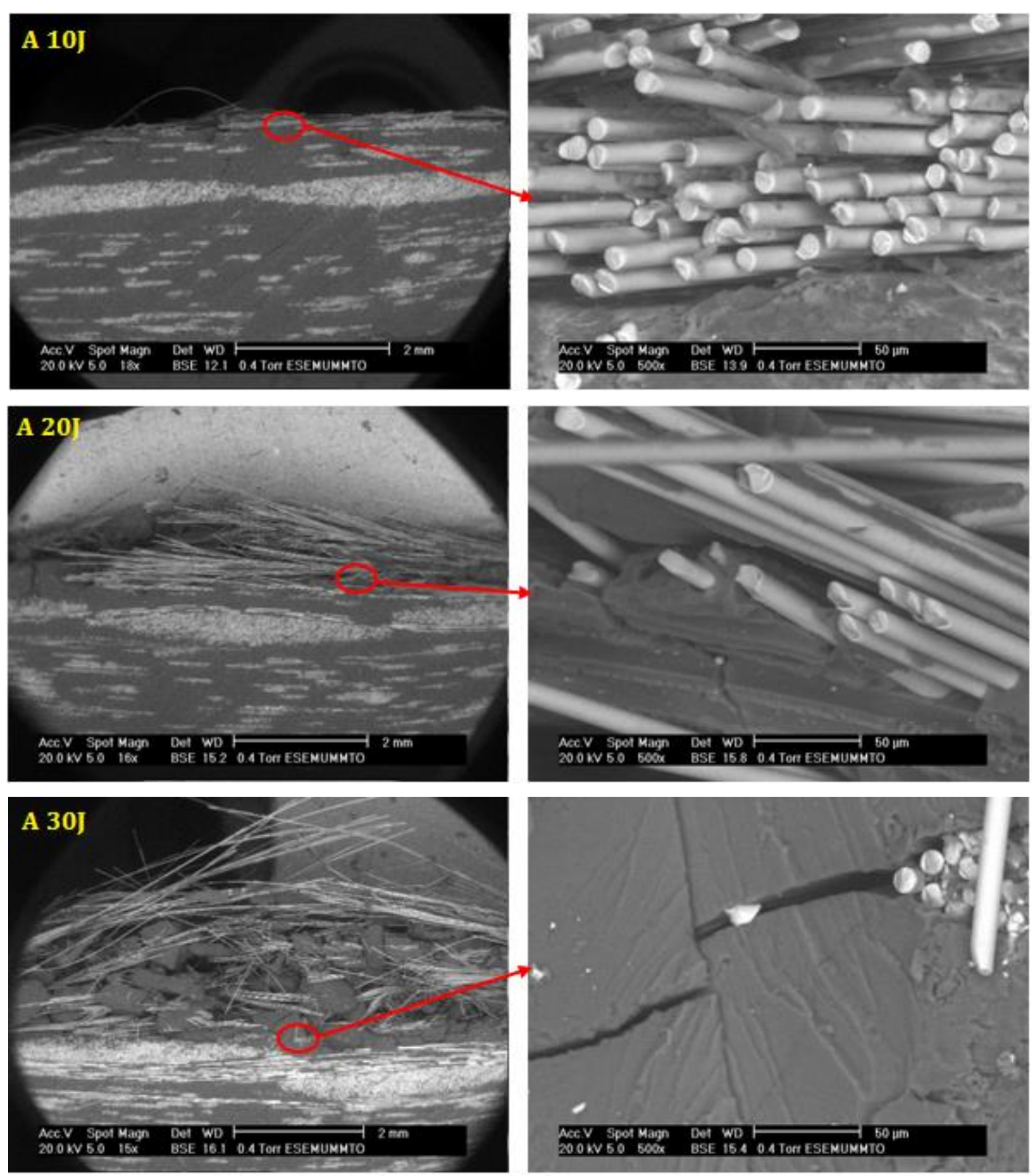

Fig.10. SEM observation of healthy specimens as a function of impact energy. 

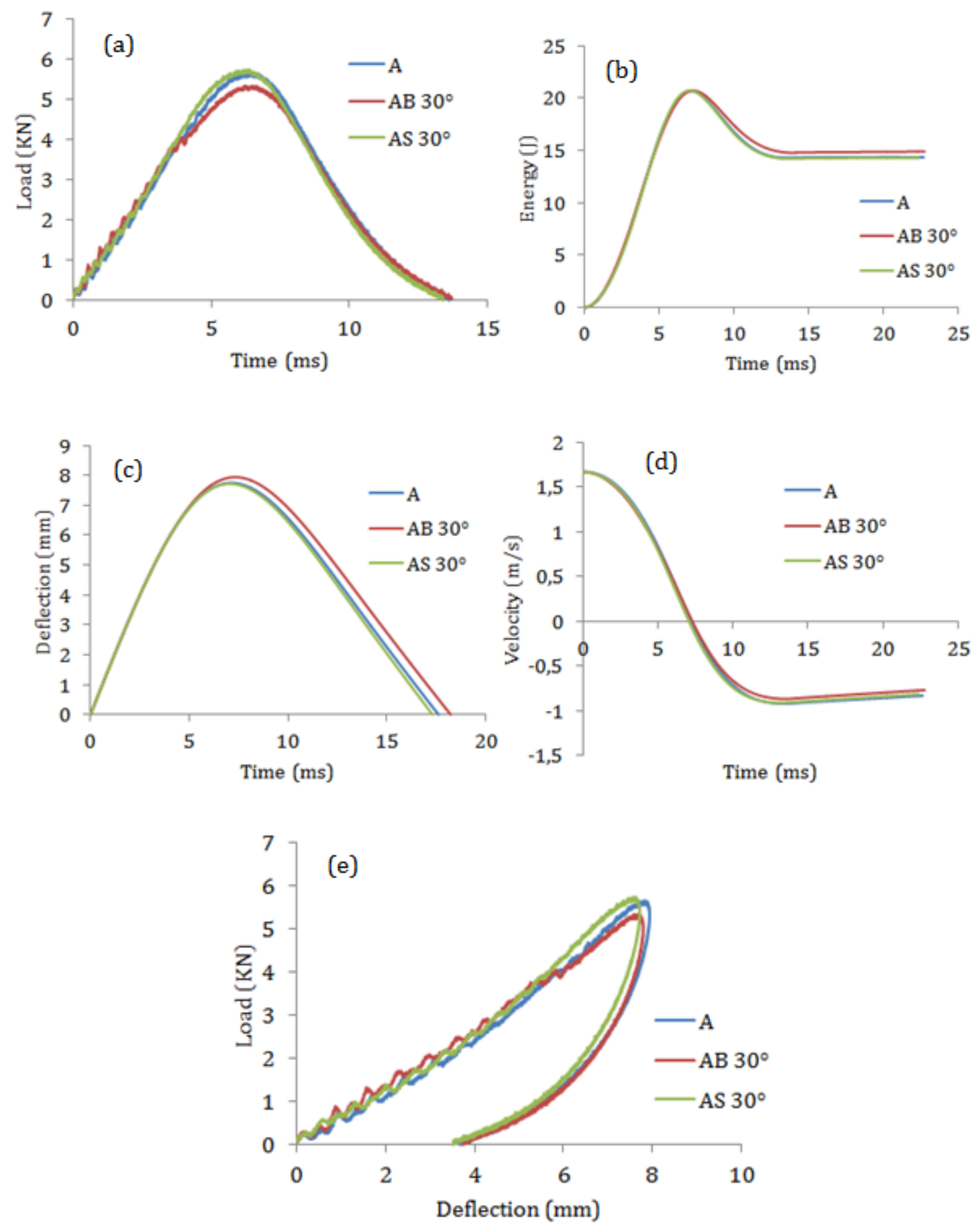

Fig. 11. Comparison of healthy material behavior/with defect/with shear: load vs. time (a), energy vs. time (b), deflection vs. time (c), velocity vs. Time (d), load vs. deflection (e). 


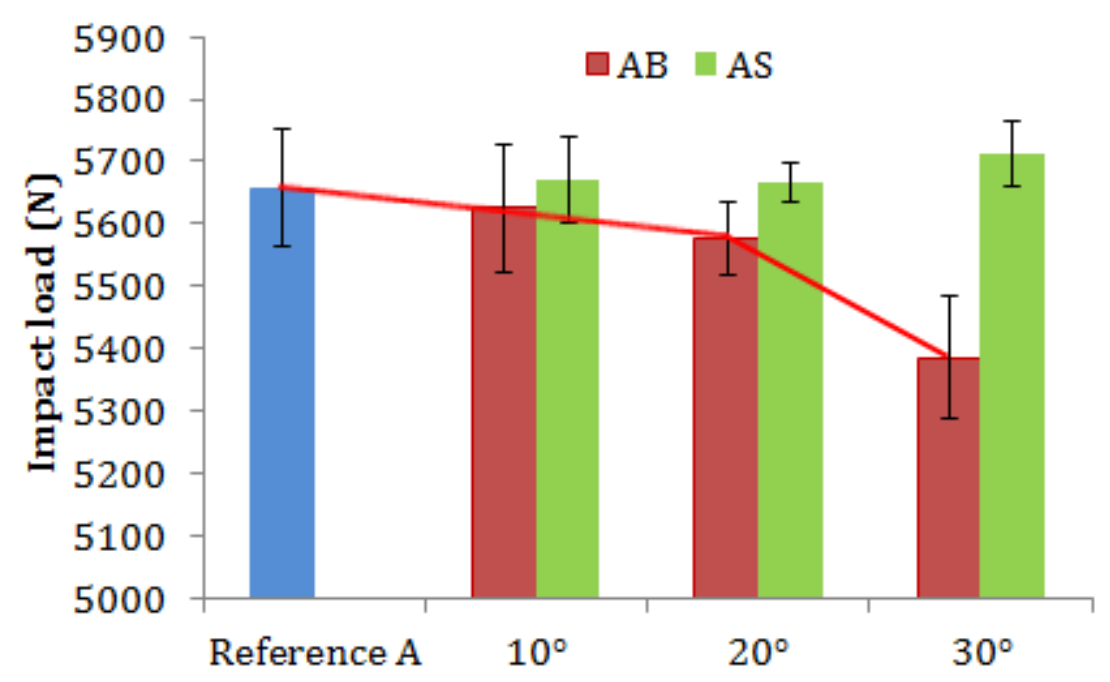

Fig.12: Comparison of the maximum load for healthy / with defects / sheared laminates as a function of the shear angle.

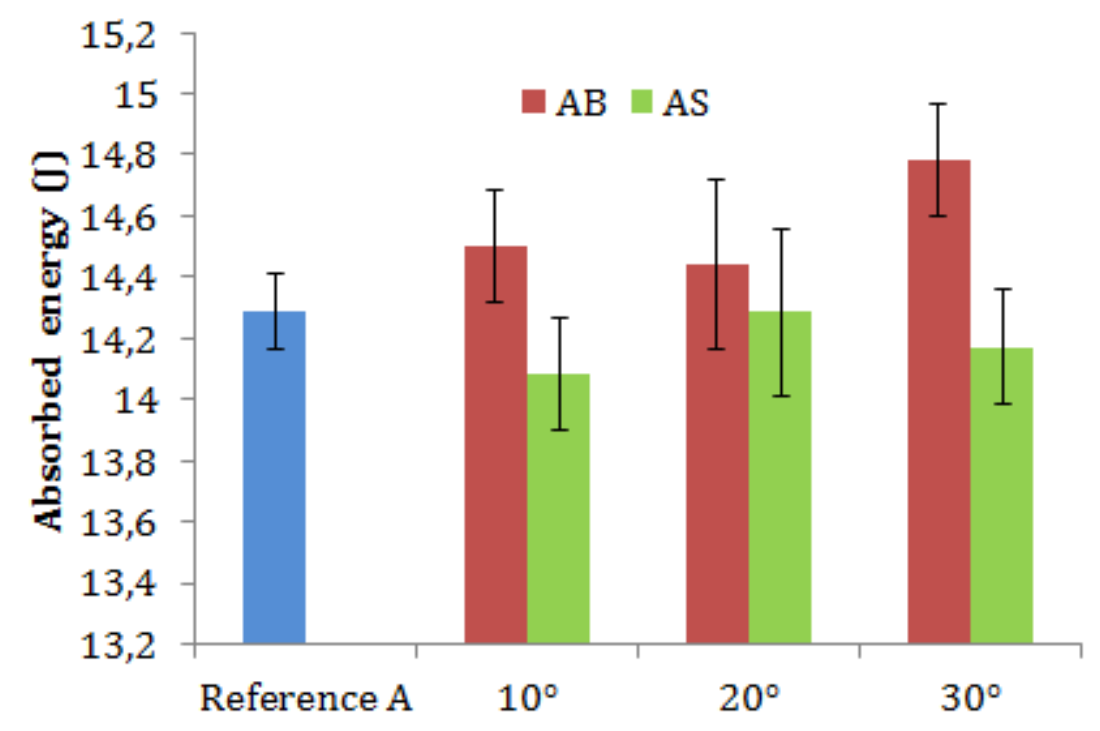

Fig.13 : Comparison of absorbed energy for healthy / with defects / sheared laminates as a function of shear angle. 

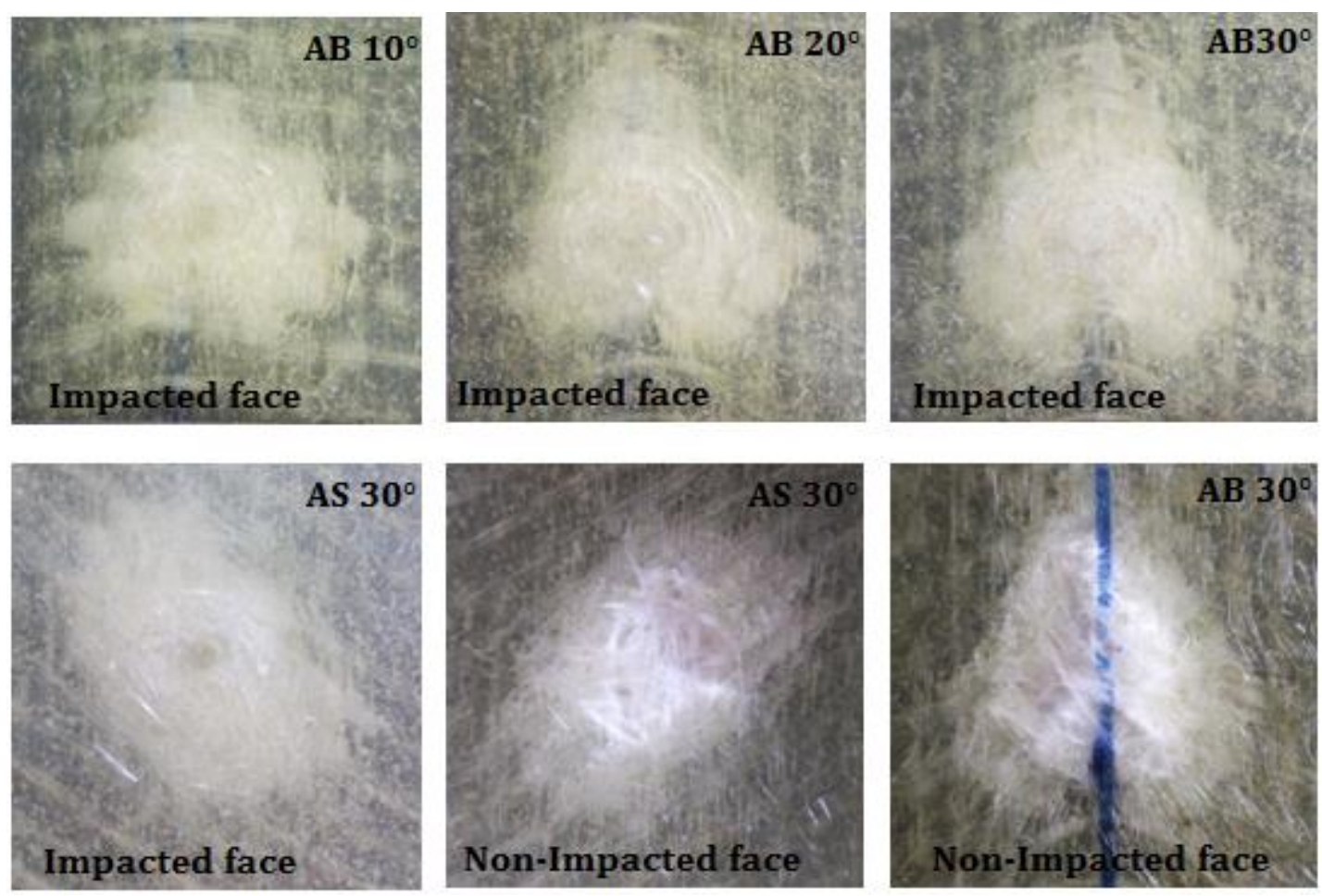

Fig. 14. Evolution of impact damage area as a function of the shear angle of specimens with calibrated defects.



Fig. 15. Evolution of the damaged area of healthy / with defects / sheared laminates as a function of the shear angle. 

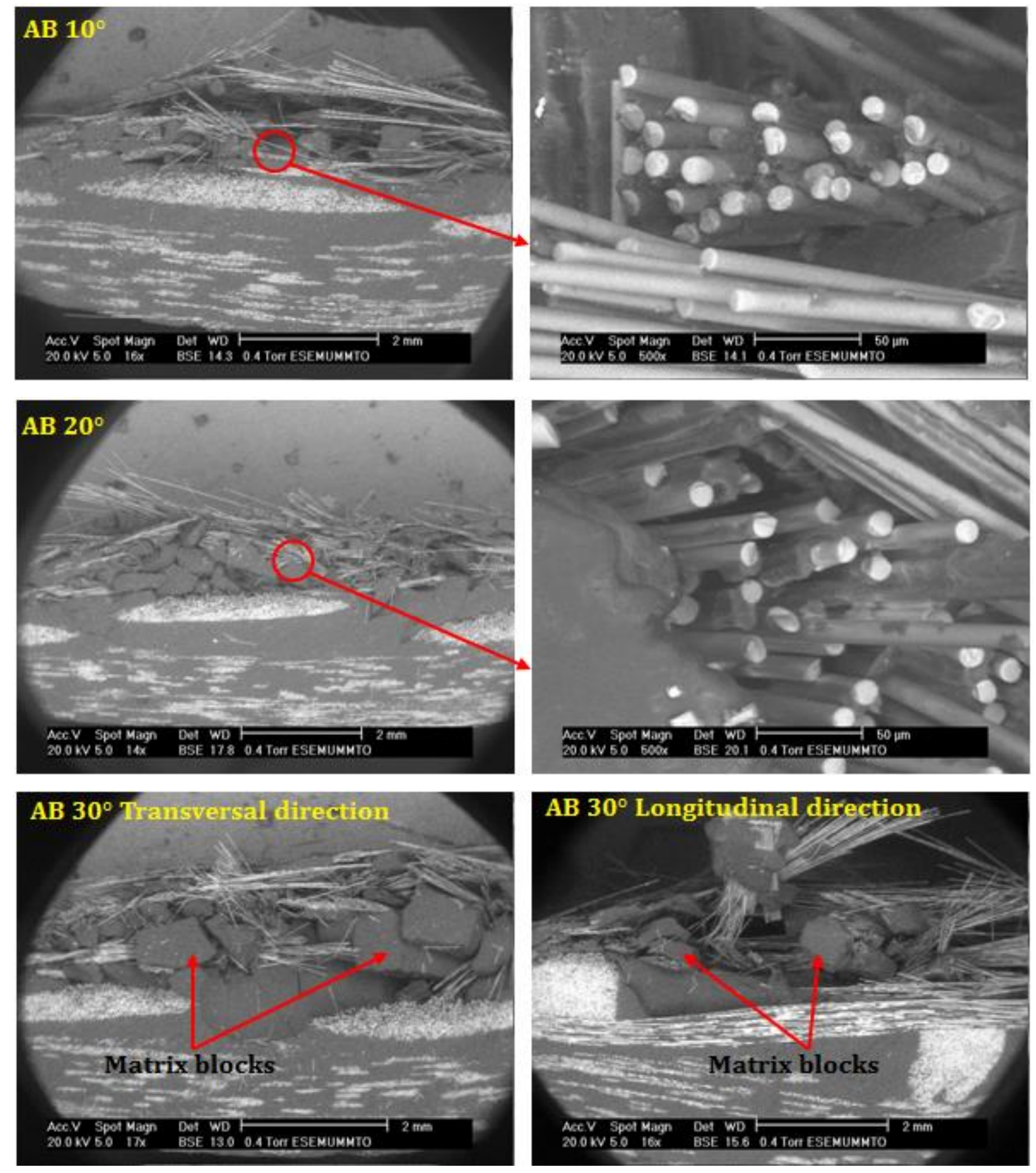

Fig. 16. SEM observation of specimens with buckles defect (AB). 

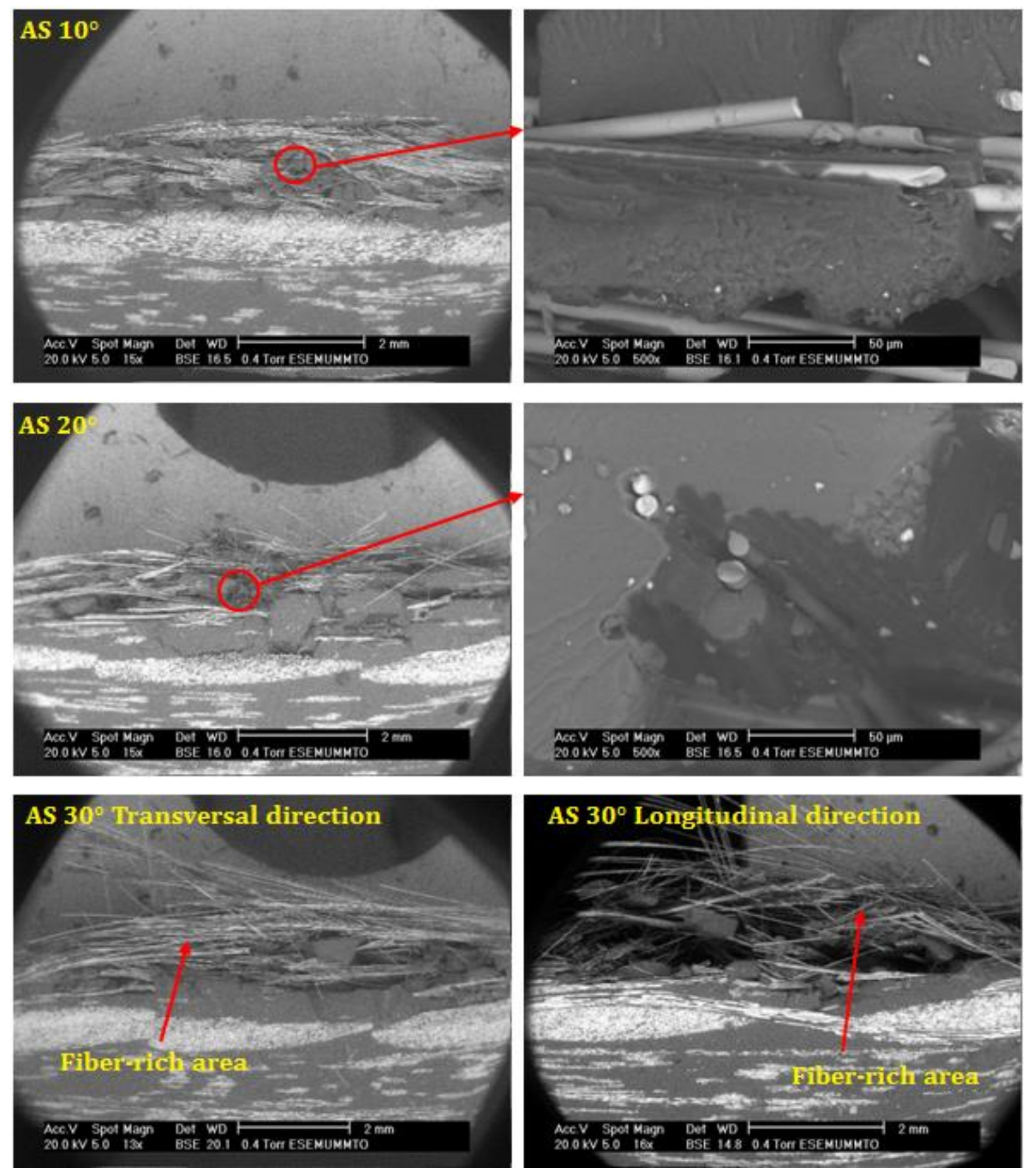

Fig. 17. SEM observation of sheared specimens (AS). 
Table 1

Average impact characteristics of reference material (Batch A).

\begin{tabular}{|c|c|c|c|c|c|c|}
\hline $\begin{array}{l}\text { Impact } \\
\text { energy } \\
\text { Eimp }(J)\end{array}$ & $\begin{array}{l}\text { Impact } \\
\text { velocity } \\
V_{\text {imp }}(\mathrm{m} / \mathrm{s}) \\
\end{array}$ & $\begin{array}{l}\text { Maximum } \\
\text { load } \\
\mathrm{F}_{\max }(\mathrm{N})\end{array}$ & $\begin{array}{l}\text { Absorbed } \\
\text { energy } \\
\text { Eabs (J) } \\
\end{array}$ & $\begin{array}{l}\text { Maximum } \\
\text { deflection } \\
\mathrm{f}_{\max }(\mathrm{mm})\end{array}$ & $\begin{array}{l}\text { Damaged profile } \\
\text { height } \\
(\mathrm{mm})\end{array}$ & $\begin{array}{l}\text { Damaged } \\
\text { area } \\
\left(\mathrm{mm}^{2}\right)\end{array}$ \\
\hline $10 \mathrm{~J}$ & 1.18 & $3664 \pm 29$ & $6.76 \pm 0,09$ & $5.78 \pm 0,11$ & $0.77(21 \%)$ & $670 \pm 38$ \\
\hline 20J & 1.68 & $5657 \pm 93$ & $\begin{array}{l}14.42 \pm \\
0,12\end{array}$ & $7.81 \pm 0,13$ & 1.27 (35\%) & $1037 \pm 53$ \\
\hline $30 \mathrm{~J}$ & 2.05 & $7265 \pm 84$ & $\begin{array}{l}23.05 \pm \\
0,38\end{array}$ & $9.48 \pm 0,10$ & $1.97(53 \%)$ & $1264 \pm 25$ \\
\hline
\end{tabular}

\section{Table 2}

Average impact characteristics of laminates with calibrated defect and shear.

\begin{tabular}{llllll}
\hline Batches & $\mathrm{F}_{\max }(\mathrm{N})$ & $\mathrm{E}_{\text {abs }}(\mathrm{J})$ & $\mathrm{f}_{\max }(\mathrm{mm})$ & $\begin{array}{c}\text { Damaged profile } \\
\text { height }(\mathrm{mm})\end{array}$ & $\begin{array}{c}\text { Damaged area } \\
\left(\mathrm{mm}^{2}\right)\end{array}$ \\
\hline $\mathrm{AB} 10^{\circ}$ & $5625 \pm 104$ & $14.50 \pm 0.40$ & $8.11 \pm 0.23$ & $1.92(51 \%)$ & $759 \pm 36$ \\
$\mathrm{AB} 20^{\circ}$ & $5577 \pm 57$ & $14.44 \pm 0.14$ & $8.04 \pm 0.23$ & $2.59(67 \%)$ & $908 \pm 44$ \\
$\mathrm{AB} \mathrm{30}$ & $5386 \pm 99$ & $14.78 \pm 0.25$ & $7.97 \pm 0.19$ & $3.13(88 \%)$ & $1070 \pm 64$ \\
$\mathrm{AS} 10^{\circ}$ & $5668 \pm 69$ & $14.08 \pm 0.18$ & $8.08 \pm 0.28$ & $1.58(40 \%)$ & $739 \pm 33$ \\
$\mathrm{AS} \mathrm{20} 0^{\circ}$ & $5666 \pm 32$ & $14.28 \pm 0.27$ & $8.25 \pm 0.26$ & $1.90(50 \%)$ & $831 \pm 15$ \\
$\mathrm{AS} \mathrm{30}$ & $5712 \pm 50$ & $14.17 \pm 0.18$ & $7.75 \pm 0.23$ & $2.04(52 \%)$ & $1033 \pm 96$ \\
\hline
\end{tabular}

